NASA Technical Memorandum 106735

\title{
Evaluation of Wiring Constructions for Space Applications
}

Ahmad N. Hammoud and Mark W. Stavnes

NYMA, Inc.

Engineering Services Division

Brook Park, Ohio

John E. Dickman

National Aeronautics and Space Administration

Lewis Research Center

Cleveland, Ohio

Linda A. Burkhardt, Lynn M. Woodford,

James R. Ide and Ed Muegge

McDonnell Douglas Aerospace

St. Louis, Missouri

Prepared for the

1994 International Symposium on Electrical Insulation

sponsored by the IEEE Dielectrics and Electrical Insulation Society

Pittsburgh, Pennsylvania, June 5-8, 1994

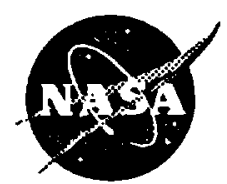

(NASA-TM-106735) EVALUATION OF

N95-13194

WIRING CONSTRUCTIONS FOR. SPACE

APPLICATIONS

(NASA. Lewis Research

(enter) 60

Unclas

National Aeronautics and Space Administration 


\section{EVALUATION OF WIRING CONSTRUCTIONS FOR SPACE APPLICATIONS}

\author{
Ahmad N. Hammoud and Mark W. Stavnes \\ Nyma, Inc. \\ NASA Lewis Research Center \\ 2001 Aerospace Parkway \\ Brook Park, Ohio 44142
}

\begin{abstract}
A NASA Office of Safety and Mission Assurance (OS\&MA) program to develop lightweight, reliable, and safe wiring insulations for aerospace applications is being performed by the NASA Lewis Research Center (LeRC). As part of this effort, a new wiring construction utilizing high strength PTFE (Poly Tetrafluoroethylene) as the insulation has been tested and compared with the existing military standard polyimidebased MIL-W-81381 wire construction. Electrical properties which werc investigated included ac corona inception and extinction voltages (sea level and $60,000 \mathrm{feet}$ ), time/current to smoke, and wire fusing time. The two constructions were also characterized in terms of their mechanical properties of flexural strength, abrasion resistance $\left(23^{\circ} \mathrm{C}\right.$ and $\left.150^{\circ} \mathrm{C}\right)$, and dynamic cut-through $\left(23^{\circ} \mathrm{C}\right.$ to $\left.200^{\circ} \mathrm{C}\right)$. The results obtained in this testing effort are presented and discussed in this paper.
\end{abstract}

\section{INTRODUCTION}

Electrical wiring is used extensively on spacecraft and satellites for power management and distribution, control and command, and data transmission. The reliability of the wiring systems when exposed to the harsh environments of space is very critical to the success of the mission and the safety of the crew. Polyimide film insulation is widely used in clectrical wiring systems of acrospace applications, due to its high diclectric strength, low weight, non-flammability, and high temperature capability. However, new failure modes have been reported recently by the aerospace community, in which degraded polyimide insulation materials become conductive upon arc initiation. Propagation of the arc along the wiring harness, a phenomenon called arc tracking, can occur under these conditions. Various wiring system failures have proven in the past to be very costly in terms of loss of expensive equipment and the loss of lives. Therefore, identifying new insulation constructions which are resistant to arc tracking is important for assuring the safety of future NASA missions.

A NASA OS\&MA program whose objective is to increase the safety of spacecraft wiring systems is being managed at NASA LeRC. The program uses a database of testing information on the various candidates to replace MIL-W81381 , and identifies the requirements which are relevant to the NASA missions. Specifically, an extensive testing database was developed by the Air Force Wright Laboratory under contract with McDonnell Douglas Aerospace Company (MDA) which thoroughly addressed the aircraft operational environments [1]. Additionally, a limited amount of testing

\author{
Linda A. Burkhardt, Lynn M. Woodford, \\ James R. Ide and Ed Muegge \\ McDonnell Douglas Aerospace \\ P.O. Box 516 \\ St. Louis, Missouri 63166
}

data already exists for new constructions in the NASA environments, and is contained in the NASA MAPTIS database [2]. By determining the operational environments for NASA, as compared to the aircraft environments, the additional operational requirements for NASA were determined and the unique tests to be performed were revealed [3].

One of the wire insulation constructions which was identified as a possible candidate to replace MIL-W-81381 in the Air Force program was manufactured by W.L. Gore and Associates and was designated as High Strength Crush Resistant PTFE (HS-725). This construction was promising through the initial phases of the Air Force program, but was dropped from further testing due to the military's prohibition of single source part suppliers. Because NASA does not prohibit single source suppliers, it was decided to further test this wiring construction. The first stage of the NASA test program is to fully evaluate the HS-725 wire construction for the aircraft environment and begin its assessment for space use.

To maintain continuity with the Air Force program, and to make use of their extensive experience, MDA was chosen to perform the testing of these samples. This part of the test program consisted of the following tests according to SAE AS-4373 [4]:
Wire Fusing Time
Flex Life
Time/Current to Smoke
Abrasion Dynamic Cut Through Corona Inception and Extinction

The test program compared AWG \#20 sample of MIL-W$81381 / 7$ and the HS-725. The HS-725 uses a multi-layer fluoropolymer insulation construction with a $6 \mathrm{mil}$ nominal wall. The layers are constructed as follows:

1. 0.75 mil expanded PTFE

2. 1.0 mil PTFE

3. 1.5 mil HSCR TM PTFE

4. 1.5 mil HSCRTM PTFE

5. 2.0 mil PTFE

\section{HS-725/MIL-W-81381 TEST RESULTS}

\section{Time Current to Smoke Test}

The time/current to smoke test was used to determine the current and duration required to produce smoke from a 
finished wire specimen. Six 12 inch samples of each wire type were used in this test. One-half inch of insulation was removed from each end and the sample was suspended in free air between two terminal blocks. A black back drop was used to facilitate the observation of smoke being produced. Power was supplied by a F-15 150 amp (A) transformer-rectifier unit with a $100 \mathrm{~A}, 100 \mathrm{mV}$ Weston shunt in series. The test began by raising the current through the specimen to $10 \mathrm{~A}$. Once 10 A of current was achieved, a stopwatch was started. The specimen was visually monitored to detect smoke against the black background. After 30 seconds (s) at $10 \mathrm{~A}$, the current was increased $5 \mathrm{~A}$ for an additional $30 \mathrm{~s}$. This process was repeated until smoke was detected.

The results of the time/current to smoke test are shown in Figure 1. Both the MIL-W-81381 and HS-725 samples could withstand $35 \mathrm{~A}$ for the full $30 \mathrm{~s}$. At the $40 \mathrm{~A}$ level, the MILW-81381 withstood the full $30 \mathrm{~s}$ while the HS-725 samples averaged $29 \mathrm{~s}$ of current flow until smoke appeared. When a 45 A current was applied, the HS-725 construction smoked immediately and the MIL-W-81381 lasted an average of $20 \mathrm{~s}$.

\section{Wire Fusing Time Test}

The wire fusing time test was used to determine the time required to interrupt an insulated wire sample during an overcurrent condition. Six 12 inch samples of each wire type were used in this test. One-half inch of insulation was removed from each end and the sample was suspended in free air between two terminal blocks. Power was supplied by the transformer-rectifier unit with a series shunt as in the previous test. The DC constant current supply was set to $60 \mathrm{~A}$ which is 2.5 times the maximum rated current of 20 AWG silver plated copper conductor $(24 \mathrm{~A})$. The current was supplied to the specimen by closing a relay, and the time to interrupt was recorded.

The results of the wire fusing time test are shown in Figure 2. The MIL-W-81381 samples averaged $27.67 \mathrm{~s}$ to interrupt while the HS-725 samples averaged $20.17 \mathrm{~s}$. It should be noted that all of the samples tested were fairly consistent across the specimen base. The MIL-W81381 wire samples averaged $7.5 \mathrm{~s}$ longer to interrupt in an over-current condition than did the HS-725 wire samples.

\section{Flex Life Test}

The flex life test was used to determine the mechanical flex strength of the conductor and insulation. Six 18 inch samples of each wire type were used in this test. One-half inch of insulation was removed from one end of each wire and a spade lug was attached. The other end was stripped of two inches of insulation and an instrument lead was attached using a crimp splice. Two $6 \mathrm{X}$ mandrels were covered with 5 mil Teflon tape to reduce friction. The specimen was clamped to a flex arm six inches above the mandrels with a 2 mil gap separating the wire from each mandrel. A 7 pound weight (20\% of the conductor's break strength) was attached to the other end of the conductor to provide tension. The specimens were flexed $90^{\circ}$ in one direction, back to vertical, $90^{\circ}$ in the other direction and back to vertical for one cycle. The flex arm was cycled at a rate of 30 cycles per minute until a $115 \%$ increase in the conductors resistivity was noted or a crack in the insulation occurred.

The results of the flex life test are shown in Figure 3. On average, the flex life of the MIL-W-81381 wire was twice that of the HS-725 construction. The failure mode of the HS725 construction was increasing resistance indicating strand breakage. The primary failure mode of the MIL-W-81381 was a breakage of the insulation and conductor at the point of flexure. It should be noted that the cycles to failure varied widely among the same sample types.

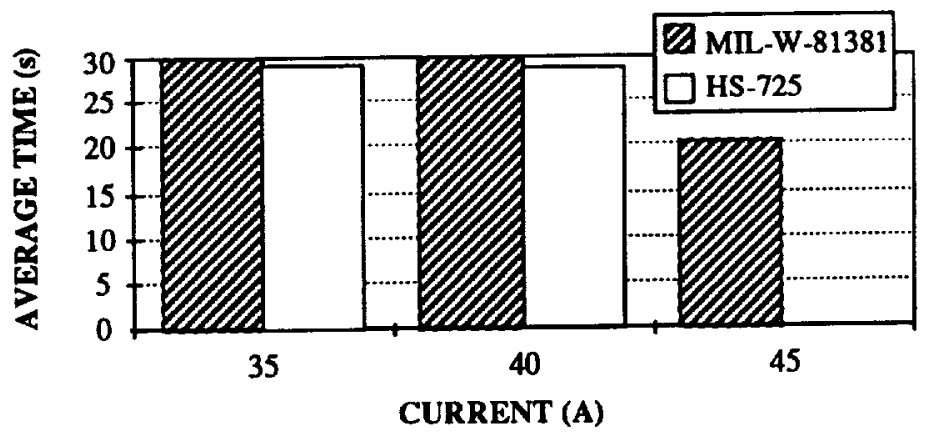

Figure 1. Time/Current to Smoke Test Results.

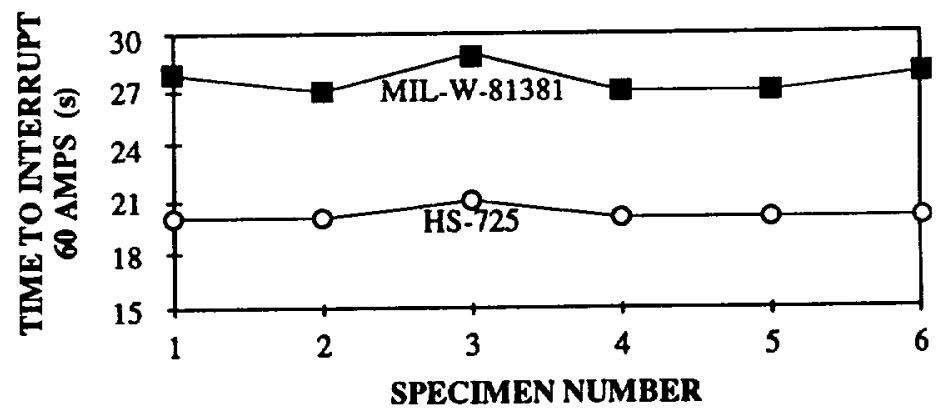

Figure 2. Wire Fusing Time Test Results.

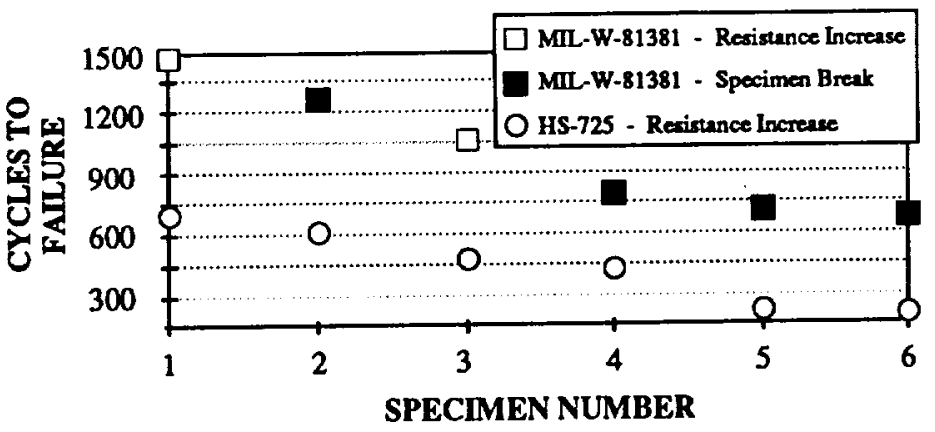

Figure 3. Flex Life Test Results. 
Dynamic Cut Through Test

The dynamic cut through test was used to evaluate the resistance of the insulation of a wire specimen to the penetration of a cutting surface. The test was conducted at the following temperatures: ambient, $70^{\circ} \mathrm{C}, 150^{\circ} \mathrm{C}$ and $200^{\circ} \mathrm{C}$. Eight 5 inch samples of each wire type were tested under each condition. The specimens were mounted on a flat steel plate with a 12 VDC detection circuit monitoring for continuity between the conductor and cutting tool. The cutting tool was a 20 mil tungsten carbide rod with a 4-6 mil finish. The cutting tool was pressed against the wire at a rate of 0.2 inches per minute until electrical continuity was detected or cut through was recorded.

The results of the dynamic cut through test are shown in Figure 4. At ambient temperature, the MIL-W-81381 construction withstood 3.5 times the force of the HS-725 construction. As temperatures increased, so did the performance margin between the MIL-W-81381 and the HS-725 samples. At $200^{\circ} \mathrm{C}$, the MIL-W-81381 withstood 5 times more force than the HS-725 samples.

\section{Abrasion Test}

The abrasion test was used to provide a relative abrasion resistance evaluation of wire insulations at ambient temperature and $150^{\circ} \mathrm{C}$. Four 12 inch samples of each wire type were used for this test. The abrading tool consisted of a 0.020 inch diameter counter balanced rod with an inherent $10 \mathrm{gram}$ force. The rod was attached to an AC motor that moved the rod in a one inch linear path over the specimen at a rate of 60 cycles per minute. The test was conducted until the abrading tool made electrical contact with the wire conductor. Each sample was tested with a weight of one, two and three pounds attached to the abrading rod. The number of cycles to failure was recorded for each condition.

The results of the abrasion test at ambient temperature are shown in Figure 5. The MIL-W-81381 samples withstood approximately 4 times more cycles than the HS-725 samples with weights of one and two pounds applied. The performance gap with the three pound weight narrowed, but the MIL-W-81381 still sustained twice as many cycles as did the HS-725 wire.

The results of the abrasion test at an elevated temperature of $150^{\circ} \mathrm{C}$ are shown in Figure 6. In this case, the MIL-W-81381 wire withstood approximately 6 times more abrasion cycles than the HS-725 in all test weight conditions.

\section{Corona Inception and Extinction Test}

A $400 \mathrm{~Hz}$ power source was used to determine the AC corona inception and extinction voltages. Tests were performed on

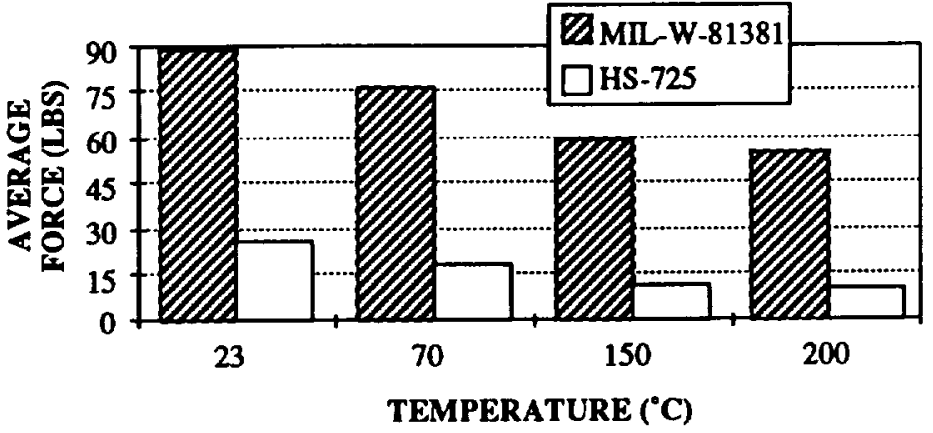

Figure 4. Dynamic Cut Through Test Results.

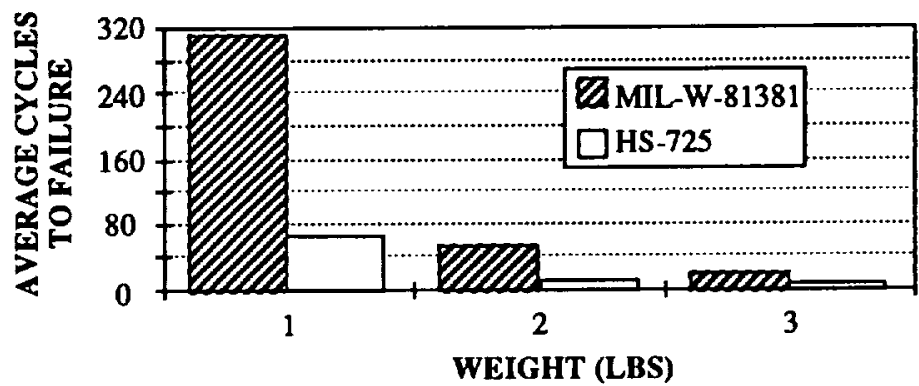

Figure 5. Abrasion Test Results at Ambient Temperature.

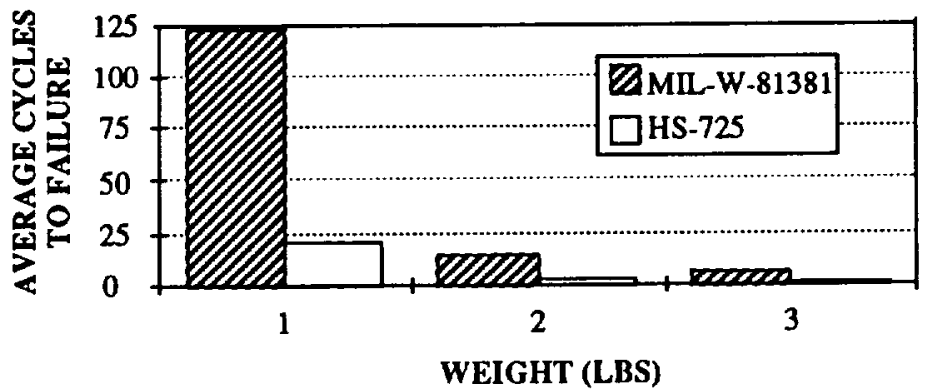

Figure 6. Abrasion Test Results at $150^{\circ} \mathrm{C}$.

wire samples that were exposed to ambient temperature-sea level and ambient temperature-60,000 feet. Five 34 inch specimens of each wire sample were wrapped for 10 equally spaced turns around a 10X mandrel. The ends of the wires were twisted, crimped together and connected to a power strip. The mandrel was connected to the $\mathrm{AC}$ retum line through a $50 \mathrm{k} \Omega$ resistor. Power was supplied at a rate no greater that $50 \mathrm{~V} / \mathrm{s}$ until continuous corona discharges were observed on the positive half cycle of the $\mathrm{AC}$ waveform. After the inception voltage was determined, the voltage was lowered gradually until the discharges were no longer detectable and this voltage was recorded as the extinction voltage.

Corona results at sea level are shown in Figure 7. In this test, the inception and extinction voltages for the HS-725 specimens were consistently $200 \mathrm{~V}_{\mathrm{rm}}$ higher than those of 


\section{FUTUREWORK}

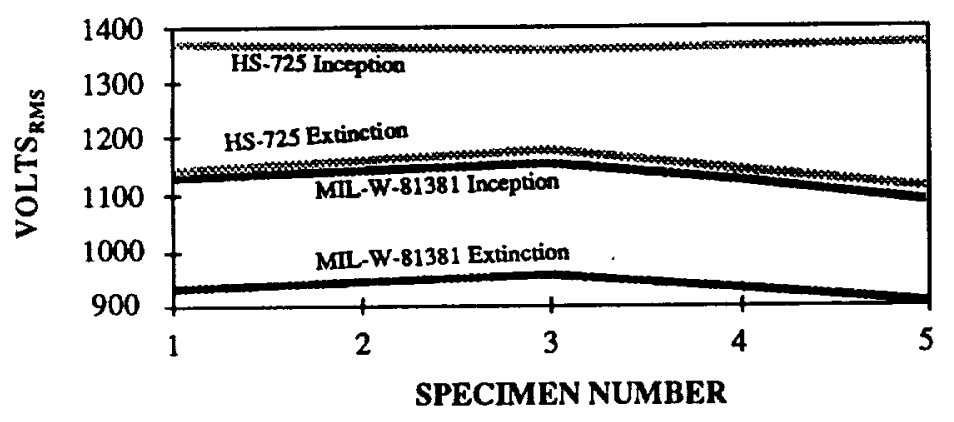

Figure 7. Corona Test Results at Sea Level.

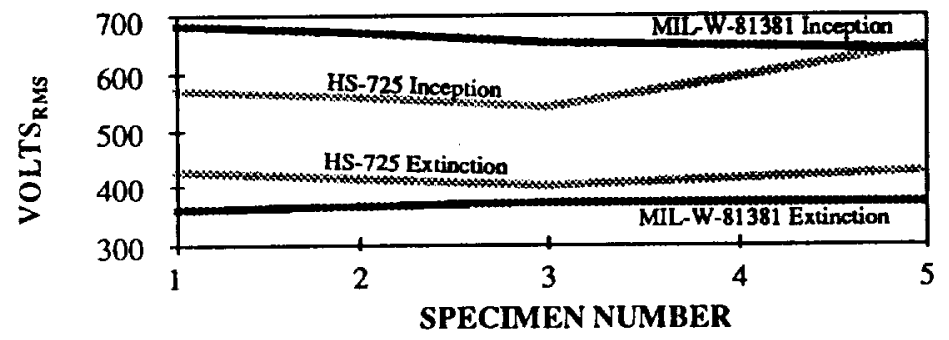

Figure 8. Corona Test Results at Altitude.

the MIL-W-81381 samples. In both cases, the differential voltage required to extinguish the corona is about $200 \mathrm{~V}_{\mathrm{mms}}$.

Corona results at altitude $(60,000 \mathrm{feet})$ are shown in Figure 8. The MIL-W-81381 inception voltage is now higher than the HS-725 construction and the extinction voltages are comparable. The differential voltage required to extinguish the corona, however, is approximately $300 \mathrm{~V}_{\mathrm{mm}}$ for the MIL$\mathrm{W}-81381$ and $150 \mathrm{~V}_{\text {rms }}$ for the HS-725 construction.

\section{CONCLUSIONS}

The tests performed to date in this program pointed out one striking difference between the MIL-W-81381 and HS-725 constructions -- performance at elevated temperatures. From the ability to withstand overload currents without smoking to the ability to withstand mechanical stress, the HS-725 construction clearly did not match the performance of the MIL-W-81381. Additionally, mechanical performance of the MIL-W-81381 was generally superior to the HS-725 construction. In some areas, such as corona and wire fusing time, both constructions were essentially equivalent in performance. Based upon a comparison of the HS-725 construction to the performance of the MIL-W-81381 in these tests and the other wire candidates from the Air Force program [1], it was decided not to perform additional tests on the HS-725 wiring construction because of the importance of mechanical properties to NASA applications. The HS-725 construction has favorable qualities and may be applicable for other aerospace and terrestrial applications.
Further testing is planned to complete the database for the NASA unique operational environments and testing requirements using the top hybrid candidates from the Air Force program [1]. These include outgassing, corona discharge and arc tracking in vacuum, flammability and anc tracking in enriched oxygen, the effect of microgravity on flammability and arc tracking, space environment and fluid exposure testing, temperature extremes and cycling. The wiring constructions which perform the best in the various NASA environments will be proposed as candidates for use in NASA applications.

\section{ACKNOWLEDGMENT}

The authors would like to thank Dr. Daniel R. Mulville, Director of NASA HQ OS\&MA, Technical Standards Division for his continued support and technical guidance. The testing effort was performed by McDonnell Douglas Aerospace under contract NAS118580, Technology for Hyperspace Vehicles - Task \#12 Feasibility Study of New Wire Insulation Constructions for NASA Aerospace Wiring Applications issued 29 September, 1992 [5]. Work was also performed under contracts NAS3-25266 and NAS3-27186 with NASA Lewis Research Center.

\section{REFERENCES}

1. Soloman, R., Woodford, L., Domalewski, S., New Insulation Constructions for Aerospace Wiring Applications, McDonnell Aircraft Company, June 1991, WL-TR-91-4066.

2. MAPTIS - NASA Materials and Processes Technical Information System, NASA Marshall Space Flight Center, September, 1993.

3. Stavnes, M.W., Hammoud, A.N., NASA Requirements and Application Environments for Electrical Power Wiring, Sverdrup Technology, Inc., August, 1992, NASA CR-191064.

4. Aerospace Standard Test Method SAE AS-4373, Test Methods for Insulated Electric Wire. Society of Automotive Engineers, 1990.

5. Muegge, E.A., Feasibility Study of New Wire Insulation Constructions for NASA Aerospace Wiring Applications, McDonnell Douglas Aerospace TM 257.93.0060.01, May 1993. 


\begin{tabular}{|c|c|c|c|c|}
\hline \multicolumn{3}{|c|}{ REPORT DOCUMENTATION PAGE } & & $\begin{array}{l}\text { Form Approved } \\
\text { OMB No. 0704-0188 }\end{array}$ \\
\hline \multicolumn{5}{|c|}{ 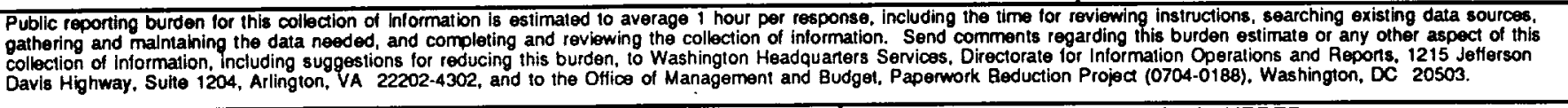 } \\
\hline 1. AGENCY USE ONLY (Leave blank) & \begin{tabular}{r|r} 
2. REPORT DATE \\
October 1994
\end{tabular} & \multicolumn{3}{|c|}{$\begin{array}{l}\text { 3. REPOAT TYPE AND DATES COVERED } \\
\text { Technical Memorandum }\end{array}$} \\
\hline \multicolumn{3}{|c|}{$\begin{array}{l}\text { 4. TITLE AND SUBTITLE } \\
\text { Evaluation of Wiring Constructions for Space Applications }\end{array}$} & \multirow{2}{*}{\multicolumn{2}{|c|}{ 5. FUNDING NUMBERS }} \\
\hline \multicolumn{3}{|c|}{$\begin{array}{l}\text { 6. AUTHOR(S) } \\
\text { Ahmad N. Hammoud, Mark W. Stavnes, John E. Dickman, Linda A. Burkhardt, } \\
\text { Lynn M. Woodford, James R. Ide, and Ed Muegge }\end{array}$} & & \\
\hline \multicolumn{3}{|c|}{$\begin{array}{l}\text { 7. PERFOAMING ORGANIZATION NAME(S) AND ADDRESS(ES) } \\
\text { National Aeronautics and Space Administration } \\
\text { Lewis Research Center } \\
\text { Cleveland, Ohio } 44135-3191\end{array}$} & \multicolumn{2}{|c|}{ E-9129 } \\
\hline \multicolumn{3}{|c|}{$\begin{array}{l}\text { 9. SPONSORING/MONITORING AGENCY NAME(S) AND ADDRESS(ES) } \\
\text { National Aeronautics and Space Administration } \\
\text { Washington, D.C. } 20546-0001\end{array}$} & 10. SP & $\begin{array}{l}\text { NSORINGMMONITOAING } \\
\text { NCY REPOAT NUMBER } \\
\text { SA TM-106735 }\end{array}$ \\
\hline \multicolumn{5}{|c|}{$\begin{array}{l}\text { 11. SUPPLEMENTARY NOTES } \\
\text { Prepared for the 1994 International Symposium on Electrical Insulation sponsored by the IEEE Dielectrics and Electrical Insulation Society, Pittsburgh, } \\
\text { Pennsylvania, June 5-8, 1994. Ahmad N. Hammoud and Mark W. Stavnes, NYMA. Inc., Engineering Services Division, 2001 Aerospace Parkway, } \\
\text { Brook Park, Ohio 44142; John E. Dickman, NASA Lewis Research Center; Linda A. Burkhards, Lynn M. Woodford, James R. Ide, and Ed Muegge. } \\
\text { McDonnell Douglas Aerospace, P.O. Box 516, St. Louis, Missouri 63166. Responsible person, John Dickman, organization code 5480, (216) 433-6150. }\end{array}$} \\
\hline \multicolumn{3}{|c|}{$\begin{array}{l}\text { 12a. DISTRIBUTION/AVAILABILTY STATEMENT } \\
\text { Unclassified - Unlimited } \\
\text { Subject Categories } 18 \text { and } 27\end{array}$} & \multicolumn{2}{|c|}{ 12b. DISTRIBUTION CODE } \\
\hline \multicolumn{5}{|l|}{ 13. ABSTRACT (Maximum 200 words) } \\
\hline \multicolumn{5}{|c|}{$\begin{array}{l}\text { A NASA Office of Safety and Mission Assurance (OS\&MA) program to develop lightweight, reliable, and safe wiring } \\
\text { insulations for aerospace applications is being performed by the NASA Lewis Research Center (LeRC). As part of this } \\
\text { effort, a new wiring construction utilizing high strength PTFE (Poly Tetrafluoroethylene) as the insulation has been tested } \\
\text { and compared with the existing military standard polyimide-based MIL-W- } 81381 \text { wire construction. Electrical properties } \\
\text { which were investigated included ac corona inception and extinction voltages (sea level and } 60,000 \text { feet), time/current to } \\
\text { smoke, and wire fusing time. The two constructions were also characterized in terms of their mechanical properties of } \\
\text { flexural strength, abrasion resistance }\left(23^{\circ} \mathrm{C} \text { and } 150^{\circ} \mathrm{C}\right) \text {, and dynamic cut-through }\left(23^{\circ} \mathrm{C} \text { and } 200^{\circ} \mathrm{C}\right) \text {. The results obtained } \\
\text { in this testing effort are presented and discussed in this paper. }\end{array}$} \\
\hline \multirow{2}{*}{\multicolumn{2}{|c|}{$\begin{array}{l}\text { 14. SUBJECT TERMS } \\
\text { Electrical insulation; Wire; Polyimide }\end{array}$}} & & & $\begin{array}{c}\text { 15. NUMBER OF PAGES } \\
6\end{array}$ \\
\hline & & & & $\begin{array}{r}\text { 18. PAICE CODE } \\
\mathrm{A} 02\end{array}$ \\
\hline $\begin{array}{l}\text { 17. SECUATYY CLASSIFICATION } \\
\text { OF REPORT } \\
\text { Unclassified }\end{array}$ & $\begin{array}{l}\text { 18. SECURITY CLASSIFICATION } \\
\text { OF THIS PAGE } \\
\text { Unclassified }\end{array}$ & $\begin{array}{l}\text { 19. SECURITY CLASSIFI } \\
\text { OF ABSTRACT } \\
\text { Unclassified }\end{array}$ & ATION & 20. LIMITATION OF ABSTRACT \\
\hline
\end{tabular}

